Review Article

\title{
Latest Advances in Intersphincteric Resection for Low Rectal Cancer
}

\author{
Yifan Xv (D), Jiajun Fan, Yuan Ding, Yang Hu, Yingjie Hu, Zhengjie Jiang, \\ and Qingsong Tao
}

\author{
Department of General Surgery, Zhongda Hospital, School of Medicine, Southeast University, 87 Dingjiaqiao Road, \\ Nanjing 210009, China \\ Correspondence should be addressed to Qingsong Tao; taoqs_nju@126.com
}

Received 27 April 2020; Revised 19 June 2020; Accepted 20 June 2020; Published 20 July 2020

Academic Editor: Fernando de la Portilla

Copyright () 2020 Yifan Xv et al. This is an open access article distributed under the Creative Commons Attribution License, which permits unrestricted use, distribution, and reproduction in any medium, provided the original work is properly cited.

\begin{abstract}
Background. Intersphincteric resection (ISR) has been a preferable alternative to abdominoperineal resection (APR) for anal preservation in patients with low rectal cancer. Laparoscopic ISR and robotic ISR have been widely used with the proposal of $2 \mathrm{~cm}$ or even $1 \mathrm{~cm}$ rule of distal free margin and the development of minimally invasive technology. The aim of this review was to describe the newest advancements of ISR. Methods. A comprehensive literature review was performed to identify studies on ISR techniques, preoperative chemoradiotherapy (PCRT), complications, oncological outcomes, and functional outcomes and thereby to summarize relevant information and controversies involved in ISR. Results. Although PCRT is employed to avoid positive circumferential resection margin $(\mathrm{CRM})$ and decrease local recurrence, it tends to engender damage of anorectal function and patients' quality of life (QoL). Common complications after ISR include anastomotic leakage (AL), anastomotic stricture (AS), urinary retention, fistula, pelvic sepsis, and prolapse. CRM involvement is the most important predictor for local recurrence. Preoperative assessment and particularly rectal endosonography are essential for selecting suitable patients. Anal dysfunction is associated with age, PCRT, location and growth of anastomotic stoma, tumour stage, and resection of internal sphincter. Conclusions. The ISR technique seems feasible for selected patients with low rectal cancer. However, the postoperative QoL as a result of functional disorder should be fully discussed with patients before surgery.
\end{abstract}

\section{Introduction}

Colorectal cancer is the third largest cancer in the world. The low rectum is usually defined as the lower third of the rectum within $5-6 \mathrm{~cm}$ from the anal verge [1] or $2 \mathrm{~cm}$ above the dentate line. Low rectal cancer refers to the cancer located at the lower edge of the cancer less than $5 \mathrm{~cm}$ from the anal edge. Standard surgical treatment for massively invasive rectal carcinoma located within $5 \mathrm{~cm}$ from the anal verge is abdominoperineal resection (APR) conventionally. However, the permanent colostomy often results in poor quality of life (QoL) and severe psychological trauma. The intersphincteric resection (ISR), which was first proposed by Schiessel in 1994 for more distal location, combines rectal removal with part or the whole of internal anal sphincter excision and restores by hand sewn coloanal anastomosis
[2]. ISR has nowadays been increasingly recognized to achieve a safe distal resection margin (DRM), which can be as small as $1-2 \mathrm{~cm}[3,4]$.

\section{Intersphincteric Resection}

The intersphincteric resection (ISR) is performed by ligation and dissection at the root of inferior mesenteric artery and vein, with total mesorectal excision (TME) and lateral lymph node dissection. Beyond the inferior margin of the mesorectal envelope, the puborectal muscle is separated from the rectal tube and the intersphincteric groove is entered wherever possible from above. Incision of the intersphincteric space between the internal and external anal sphincter is performed from the posterior side of the rectum by transecting the hiatal (anococcygeal) ligament [5]. To incise the 
internal sphincter deeply, a circumferential dissection is constructed on the anal mucosa at the level of dentate line in partial-ISR, between the dentate line and intersphincteric groove in subtotal-ISR, and at the intersphincteric groove in total-ISR [5] (see Figure 1), which depends on the lower border of the tumour so as to give a $1 \mathrm{~cm}$ clearance distally. The intersphincteric plane is developed circumferentially towards the cranial end to meet the plane from the abdominal dissection [6] (see Figure 2). The autonomic pelvic nerve is reserved, and a colonic J-pouch is used as a reservoir to manufacture a $5 \mathrm{~cm}$ short pouch for anastomosis in ISR [7]. In contrast, a coloplasty pouch is designed to interrupt antegrade colonic peristalsis and as an option when the pelvis is too narrow to permit a bulky colonic J-pouch anal anastomosis and the descending colon is too short to reach the anus [8]. Comparison of the stool frequency, the use of antidiarrheal medication, and continence have confirmed no significant differences between treatment with coloplasty pouch and colonic J-pouch. Patients' perceptions measured by the Fecal Incontinence Quality of Life Scale and WIS Score are also equivalent between the two techniques [9]. A crucial prerequisite is a meticulous preoperative evaluation of local tumour spread with rectal magnetic resonance imaging excluding infiltration of the external sphincter [10]. Although ISR was initially applied to treat inflammatory bowel disease, its performance in anal preservation for low rectal cancer has been supported by many studies [1113]. Molnar et al. [12] followed up 20 patients with low rectal cancer for one year after ISR, discovering that the shortterm survival rate was $100 \%$ and the median Wexner score of all patients was less than 10. Moreover, signs of local recurrence were absent, with antigen levels remaining within the reference ranges, and the incidence of complications like wound infection and postoperative pain within one year after ISR was lower than that of APR. Comparing 72 rectal cancer patients with ISR or APR for 5 years of follow-up, Molnar et al. [13] demonstrated that the 5-year overall survival rate was not influenced by surgical techniques while patients with ISR had better quality of life (QoL) postoperatively. ISR has been a feasible option to low rectal cancer patients who have a strong desire for anal preservation.

Laparoscopic intersphincteric resection (LISR) and robotic ISR (RISR) have been widely used with the proposal of $2 \mathrm{~cm}$ or even $1 \mathrm{~cm}$ rule of distal free margin and the development of minimally invasive technology in recent years [14]. Compared with the open intersphincteric resection (OISR), LISR and RISR reveal remarkable advantages such as less operation time, less blood loss, less postoperative complications, better pathological outcomes, and better survival results.

The gold standard of rectal cancer surgery is total mesorectal excision (TME) with improved survival and reduced local recurrence. TME involves precise excision of the entire rectum and pararectal lymph nodes en bloc, within an oncologic package termed the "mesorectal envelope" [15]. For patients with rectal cancer, the adequacy of the distal margin is dependent on both the risk for intramural tumour spread and the distal mesorectal lymphatic spread. Tumour cell deposits within mesorectal lymph nodes have been identified

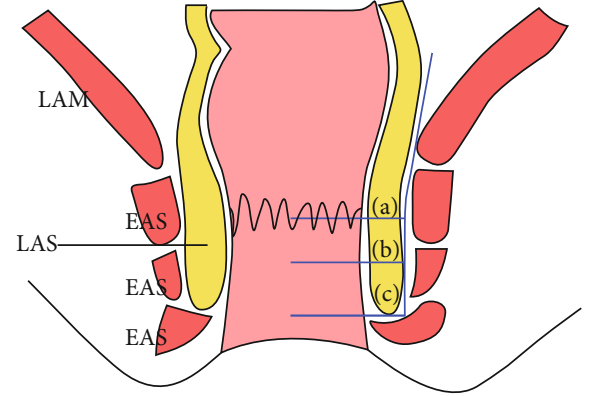

FIgURE 1: Type of ISR according to amount of excision of the internal anal sphincter. (a) Partial ISR. (b) Subtotal ISR. (c) Total ISR. EAS: external anal sphincter; IAS: internal anal sphincter; LAM: levator ani muscle.

up to $5 \mathrm{~cm}$ distal to the inferior aspect of the tumour, underlining the need to adhere to the principles of TME and engendering the concept of tumour-specific mesorectal excision (mesorectal transection $5 \mathrm{~cm}$ distal to the inferior border of the tumour) for more proximal rectal cancers. Through TME, ISR acquires sufficient tumour excision, preservation of the sphincter function, and pathologically negative margin as well. Compared with APR, ISR possesses adequate distal resection margin (DRM), sufficient circumferential resection margin (CRM), and better anal function without permanent colostomy [16, 17]. A laparoscopically accomplished coloplasty pouch is easier to anastomose to the anus without tension, and complete laparoscopic TME with ISR is considered to decrease the surgical invasiveness without any additional abdominal incisions except those created for the laparoscopic port sites.

\section{Preoperative Chemoradiotherapy}

Preoperative chemoradiotherapy (PCRT) can reduce tumour volume and ensure negative CRM, which is often perceived as the standard preoperative treatment strategy for low rectal cancer patients with ISR. PCRT enables the DRM to be

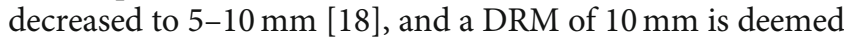
to be safe and reasonable for anal preservation $[17,19]$. Moreover, PCRT also makes a contribution to the decrease of local recurrence.

ISR following PCRT has been proved to be a valid alternative for ultralow rectal cancer patients who are reluctant to receive APR [20, 21]. Kawai et al. [22] reported a 67-year-old man with locally advanced rectal cancer accompanied by right lateral lymph node metastasis. After 6 courses of neoadjuvant chemotherapy with capecitabine, oxaliplatin, and irinotecan, remarkable tumour shrinkage was observed and the patient underwent safety ISR along with lateral lymph node dissection eventually. Okada et al. [23] also reported a 62 -year-old man with a $5 \mathrm{~cm}$ locally advanced rectal cancer in the lower rectum close to the anal with mesorectal lymph node metastases. ISR with diverting loop ileostomy was performed as an anal-preserving surgical procedure after 12 courses of capecitabine plus oxaliplatin and bevacizumab, and no remnant tumour in the rectum or lymph node metastasis was found upon the pathological examination of 


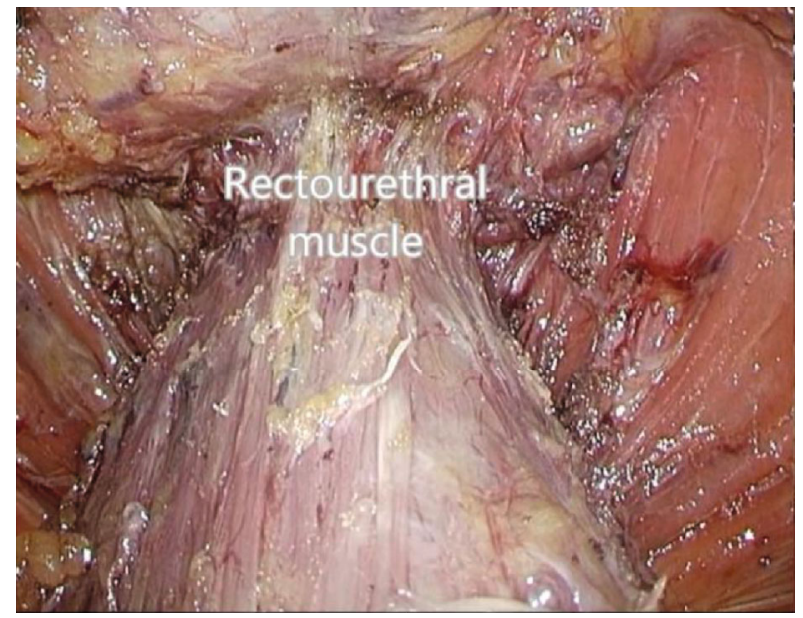

(a)

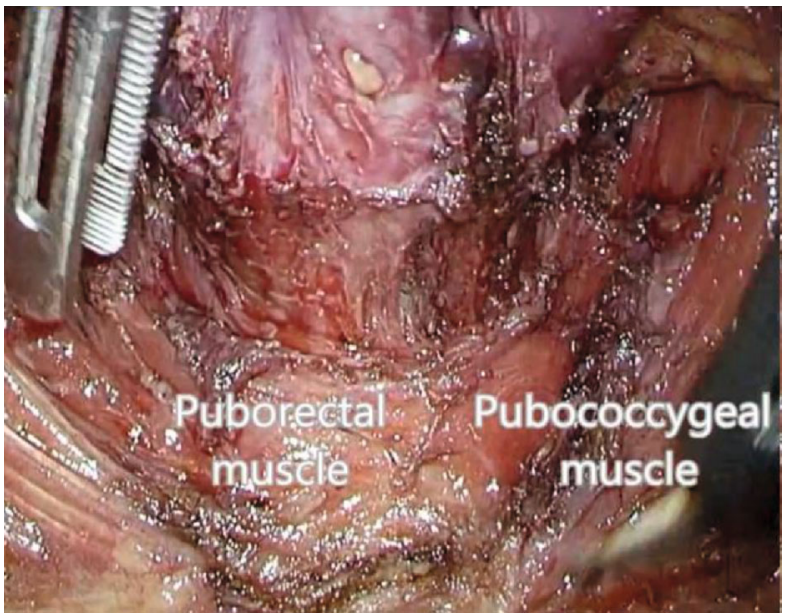

(c)

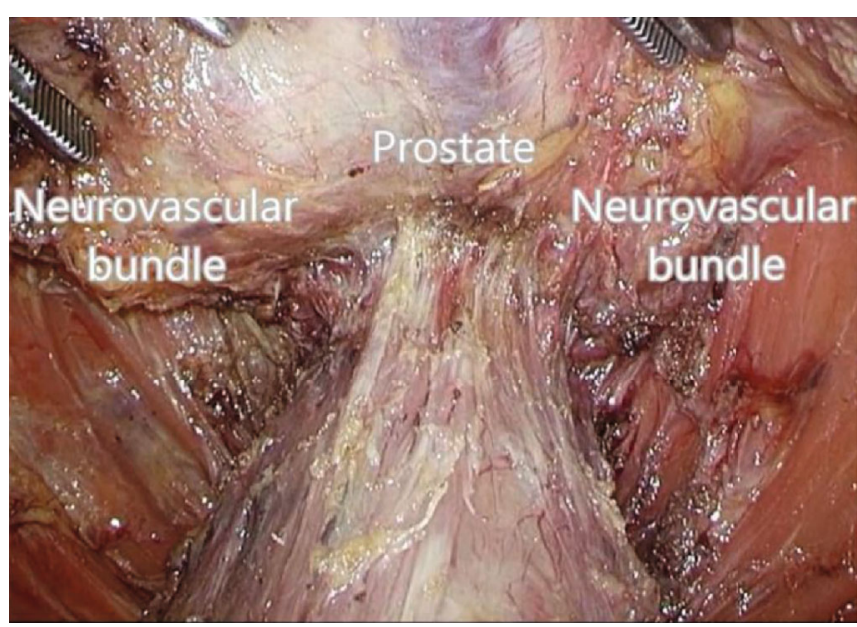

(b)

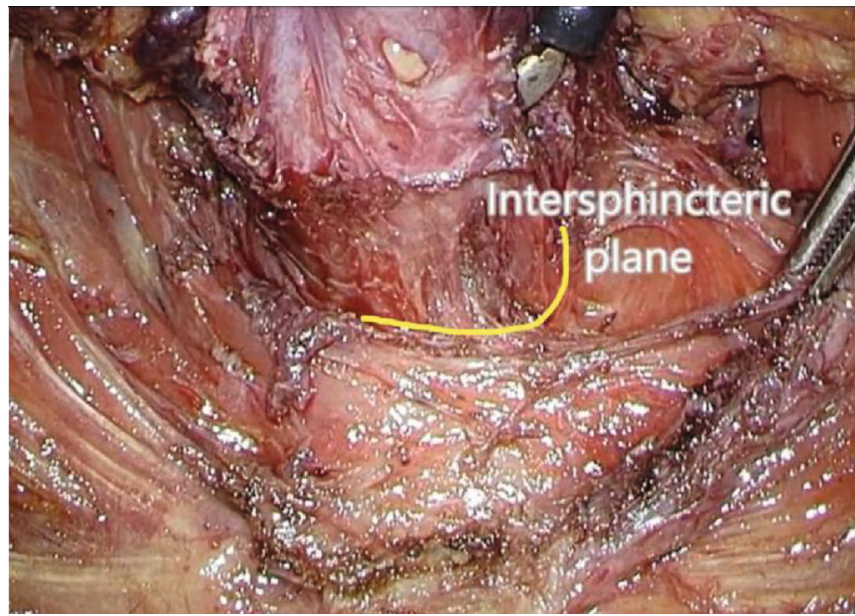

(d)

FIGURE 2: Laparoscopic procedure. (a) Dissection on the anterior side of the rectum. (b) Protection of prostate and neurovascular bundle. (c) Separation of puborectal muscle and the rectum. (d) Dissection of the intersphincteric plane.

resected specimens. No signs of recurrence were found at 12 months post operatively. Moreover, LISR with intraoperative radiotherapy using low-energy $\mathrm{X}$-rays provides an opportunity of anal reservation for patients with late-stage ultralow rectal cancer. Wang et al. [24] reported a 53-yearold female patient with rectal adenocarcinoma which was 4 $\mathrm{cm} \times 3 \mathrm{~cm}$, located $2 \mathrm{~cm}$ away from the anus and invaded the levator ani muscles. Low-energy $\mathrm{X}$-ray radiotherapy was applied during LISR, and no complications, anal dysfunction, and local recurrence occurred during follow-up.

Although many studies have proposed that PCRT makes anal preservation possible and improves prognosis, PCRT is inclined to spawn harm to anorectal function and patients' QoL, especially for patients with deep tumours. The main pathogenesis of anorectal function lesion induced by pelvic radiotherapy is anorectal irradiation. Radiation may injure the myenteric plexus and inhibit impulse conduction which has a bearing on anal sphincter lesion and fibrosis $[25,26]$. Furthermore, PCRT has been demonstrated as a critical risk factor for postoperative anal dysfunction [27], which is probably connected with pelvic ischemic changes and fibrosis
[28]. Significant reductions in anorectal maximum resting pressure and maximum crush pressure, deteriorations in the Wexner score, and disappearances of rectoanal inhibitory reflex are frequently observed in patients undergoing PCRT. Similarly, Gervaz et al. [29] discovered that PCRT prior to ISR was associated with lower urinary scores (gas, liquid, and solid incontinence) and more urinary dysfunction (aggregation and incomplete urination) than simple surgery. Nevertheless, Beraldo et al. [30] contradictorily raised that PCRT was not responsible for the deterioration of urinary symptoms. Furthermore, the implementation of ISR following PCRT is bound up with a high perioperative risk, especially for male patients with radiation colitis. Postoperative anastomotic leakage (AL) connected with chronic anastomotic stenosis [31] occurs more frequently and is more inclined to delay.

\section{Complications}

Common complications after ISR include anastomotic leakage $(\mathrm{AL})$, anastomotic stricture (AS), urinary retention, 
fistula, pelvic sepsis, and prolapse. AL often brings about postoperative AS [32], poor anorectal function, and severe sepsis followed by death. It usually occurs 3-30 days after operation, with an incidence of 3\%-20\% [33, 34]. Delayed AL is reported to occur later than 30 days, and its incidence is $0.3-4.3 \%$, accounting for about one third of all AL [35-38]. In addition to direct clinical consequences such as intra-abdominal or pelvic abscess, peritonitis, septicemia, prolonged hospitalization, and increased mortality, AL also induces pelvic organ dysfunction, anal dysfunction [39], local cancer recurrence, and increased cancer specific mortality [40].

Aggressive stage tumour, lymph node involvement, PCRT, and postoperative anemia are risk factors related to AL [41]. Besides the technical difficulties of anastomosis during operation, a predominant reason is the lack of blood supply after TME. The lower incidence of AL after colonic Jpouch compared to coloplasty pouch is conceived to stem from better proximal anastomotic blood supply. Another crucial factor for $\mathrm{AL}$ is poor pelvic drainage. Hematoma and seroma tend to gather and form in front of the sacrum after TME, consequently, infection and leakage into the anastomotic opening may promote rupture [42]. Kim et al. [43] discovered that the use of staplers increased the risk of AL, which was possibly owing to the fact that the larger diameter circular stapler caused the expansion of distal residual rectum and the attenuation of rectal wall, resulting in insufficient blood supply for the anastomosis. The colonic Jpouch with better vascularized end-to-side anastomosis shows functional superiority in reducing anastomotic dehiscence compared to the straight colonic-anal anastomosis [44]. It should be noted that PCRT is also considered to be an incentive for AL. Additionally, the incidence of recurrent $\mathrm{AL}$ is $25 \%$ [45] and it is often linked to hand-sewn anastomosis, ischaemia at the anastomotic site and a shorter interval between confirmation of healing and stoma closure.

$\mathrm{Qu}$ et al. [33] discovered that the incidence of AL after LISR (6.3\%) was lower than that after APR (10\%) in a meta-analysis owing to less bleeding and less lesion. The inflammatory reaction in LISR was also alleviated, which was conducive to the growth and healing of the anastomosis $[46,47]$. It remains controversial whether protective stoma can reduce the incidence of AL. A multicenter randomized controlled study [48] by Matthiessen et al. has pointed out that protective stoma contributed to the decrease of AL while other studies $[49,50]$ have demonstrated that it bore no relation to the prevention of AL.

Anastomotic stricture (AS), a trigger for impaired function such as fecal urgency, incontinence, and bowel obstruction, is not a negligible complication [51], and its incidence ranges from $2.5 \%$ to $19.5 \%$ [52]. ISR with hand-sewn anastomosis, postoperative radiotherapy, male, and AL [53] are independent risk factors of AS. Stapled anastomosis is associated with a low incidence for including a full layer of anal stump and excessive dilatation of the anal canal during anastomosis. Radiation injury to the anorectum is inevitable, especially when radiotherapy is administered postoperatively. Radiation not only affects the anorectum and anastomosis but also induces proctitis, subsequent anastomotic fibrosis, and AS frequently [54]. Radiotherapy constantly brings about histologic alterations such as obliterative endarteritis, tissue ischemia, necrosis, and submucosal collagen deposition, consequently resulting in transmural fibrosis and formation of strictures $[55,56]$.

The incidence of urinary retention is reported to be $4.5 \%-41.0 \%$ [57]. Urinary retention not only induces pain and urinary tract infection but also promotes complications like venous thrombosis and hospital acquired pneumonia in elderly patients. It is associated with elderly patients, low tumour location, long operation time, excessive intraoperative transfusion volume, and early postoperative removal of catheter.

\section{Oncologic Outcomes}

Local control is one of the most important oncological objectives in surgery on patients with low rectal cancer. The local recurrence rate following sphincter-saving resections for low rectal cancer has been reported to range from $4 \%$ to $13 \%$ [58], and the 5-year local recurrence rate is not significantly different from that of low anterior resection (LAR) and ARP [7]. Local recurrence is related to pathological stage, local dedifferentiation, incision margin under microscope, postoperative anemia [41], and serum CA 19-9 level before operation [59]. Among them, CRM involvement is the most critical predictor. It must be emphasized that preoperative assessment and particularly rectal endosonography are important to select suitable patients with tumours confined to the rectal wall at least in its distal part and close to the sphincter [60].

For T1-T2 tumours, careful dissection and irrigation after closure of distal stump can be performed without PCRT. However, PCRT should be considered when resection margins are estimated to be insufficient for T3 tumours [61]. For T3 and/or lymph node-positive rectal cancers in general, PCRT has a tendency to reduce local recurrence, prolong overall survival (OS), and disease-free survival (DFS) better when compared with surgery alone [62]. Moreover, it is more effective for local control, less toxic, and sphincter preservation than postoperative therapy. In addition to the reduction of tumour volume and stage, it transforms tumour into ulcerative scar, thus refraining the spread of tumour during operation and subsequent local recurrence [58]. In the study of Hohenberger et al. [63], 35 of 53 patients (66\%) received PCRT and 4 (11\%) had local recurrence while local recurrence occurred in 7 (39\%) of the 18 patients received blank control. However, it has been reported that the overall survival benefit of neoadjuvant chemotherapy has not increased, and the incidence of complications is even higher [60]. Akagi et al. [64] reported a low incidence of local recurrence (4.8\%) and a five-year survival rate of $76-97 \%$ without neoadjuvant chemotherapy.

The 3-year overall survival (OS) and disease-free survival (DFS) in the study of Sakr et al. [65] were 91.4\% and 79\%, respectively. The OS in the ultralow anterior resection (ULAR) and ISR groups were $91.4 \%$ and $91.7 \%$, respectively, while the DFS were $79 \%$ and $79.2 \%$, without any significant difference. Park et al. [66] demonstrated that the two groups shared equivalent overall 3 -year local recurrence rates when 
TABLE 1: Comparison of perioperative outcomes among OISR, LISR, and RISR.

\begin{tabular}{lccc}
\hline & OISR & LISR & RISR \\
\hline$n$ & 264 & 586 & 226 \\
Age (y) & $58.7(12.0)$ & $60.7(11.4)$ & $58.6(11.8)$ \\
Sex (male/female) & $175 / 89$ & $371 / 215$ & $159 / 67$ \\
PCRT (\%) & 29.4 & 36.8 & 67.3 \\
Distance from & $4.3(0.7)$ & $3.7(1.0)$ & $3.3(0.9)$ \\
anal verge (cm) & & & \\
Operation time (min) & $296.6(78.1)$ & $288.1(79.3)$ & $308.1(77.5)$ \\
Blood loss (ml) & $210.7(277.3)$ & $99.4(128.0)$ & $128.3(143.8)$ \\
Protective stoma (\%) & 30.0 & 44.1 & 53.3 \\
Hospital stay (d) & $16.0(6.4)$ & $11.4(5.9)$ & $10.9(4.0)$ \\
Complication & & & \\
$\quad$ Wound infection & 6 & 5 & 3 \\
Anastomotic leakage & 8 & 17 & 12 \\
Anastomotic & 3 & 10 & 5 \\
stricture & 0 & 1 & 2 \\
Bleeding & 7 & 15 & 12 \\
Ileus & 1 & 2 & 0 \\
Chylous ascites & 3 & 18 & 10 \\
Urinary retention & 2 & 6 & 0 \\
Pneumonia & 7 & 6 & 2 \\
Rectovaginal fistula & & & \\
Intra-abdominal & & & \\
abscess & & & \\
\hline
\end{tabular}

${ }^{*}$ Values are mean (s.d.).

comparing RISR with LISR. The 3-year DFS rates were 89.6\% in the robotic group and $90.5 \%$ in the laparoscopic group, respectively, without any significant difference. Unexpectedly, Portier et al. [67] investigated the oncologic outcomes of ultralow coloanal anastomosis with or without ISR for low rectal cancer, and no difference was noted in 5-year local recurrence rate and OS.

According to the meta-analysis of Zhang et al. [68], LISR had significant advantages over OISR like less operation time, less blood loss, less postoperative complications, better pathological outcomes, and superior survival results. The metaanalysis of Lee et al. [69] demonstrated that RISR shared comparable perioperative outcomes, prognosis, and survival results with LISR. Available data on comparison of perioperative (see Table 1) and oncologic (see Table 2) outcomes among OISR, LISR, and RISR are summarized from 10 articles $[66,70-78]$.

\section{Functional Outcomes}

One of the major issues for patients who undergo ISR for low rectal cancer is their QoL. Urgency, fecal incontinence (FI), frequent bowel movements, stool fragmentation, sense of incomplete evacuation, diarrhea and change in stool consistency have been highly noted. Anal dysfunction is considered to be closely related to age, PCRT, location of anastomotic
TABLE 2: Comparison of oncologic outcomes among OISR, LISR, and RISR.

\begin{tabular}{lccc}
\hline & OISR & LISR & RISR \\
\hline Tumour size (cm)* & $3.7(1.6)$ & $3.3(1.7)$ & $2.8(1.8)$ \\
Lymph node retrieved* & $15.9(9.8)$ & $14.9(9.1)$ & $13.4(7.7)$ \\
Proximal margin (cm)* & $15.6(9.6)$ & $18.7(10.9)$ & $20.7(8.0)$ \\
Distal margin (cm)* & $1.7(0.8)$ & $1.7(1.0)$ & $1.4(0.9)$ \\
Histopathological & & & \\
differentiation (\%) & & & \\
Well & 14.0 & 17.9 & 23.8 \\
Moderate & 76.6 & 74.7 & 66.7 \\
Poor & 9.4 & 6.0 & 6.0 \\
Other type & 0 & 1.4 & 3.5 \\
Stage (\%) & & & \\
pCR & 0.5 & 2.0 & 6.0 \\
I & 35.4 & 36.0 & 39.3 \\
II & 26.4 & 27.6 & 23.8 \\
III & 34.9 & 30.6 & 23.8 \\
IV & 2.8 & 3.8 & 7.1 \\
3-year LRR (\%) & 7.1 & 4.1 & 8.5 \\
3-year DFS (\%) & 79.3 & 84.5 & 85.8 \\
3-year OS (\%) & 84.5 & 89.3 & 94.2 \\
5-year LRR (\%) & 2.0 & 6.6 & 8.7 \\
5-year DFS (\%) & 71.0 & 76.3 & 80.6 \\
5-year OS (\%) & 82.0 & 86.7 & 88.5 \\
\hline Values & & &
\end{tabular}

${ }^{*}$ Values are mean (s.d.).

LRR: local recurrence rate; DFS: disease-free survival; OS: overall survival.

stoma, growth of anastomotic stoma, tumour stage, and resection of internal anal sphincter, while the length of sphincteric resection (upper third or half) does not matter for the functional outcome $[60,79,80]$. PCRT is perceived to be linked to pelvic ischemic changes and fibrosis [28], and the main pathogenesis of anorectal dysfunction caused by pelvic radiotherapy is irradiation for myenteric plexus lesion and restrain of impulse conduction. It can also damage the anal sphincter and promote fibrosis $[25,26]$ directly. In addition, Shiokawa et al. [81] has confirmed the negative effect of extensive internal sphincter resection on anal function. Huang et al. [82] compared the anal function after LISR with OISR, and the result showed that the ratios of patients with good continence were $87.1 \%$ and $87.5 \%$, respectively, during a mean follow-up of 52.0 months.

Clinical evaluation of anal function such as enhanced frequency of defecation, urgent defecation, difficulty in defecation, and FI has not been uniformed until now. The Jorge Incontinence Score, Kirwan Grade, and Wexner score are frequently used assessments. Anorectal manometry (ARM) is an objective evaluation and is widely employed for the differential diagnosis of resting and pressure reduction in patients with FI $[83,84]$. High-resolution anorectal manometry (HR-ARM) is reliable for the evaluation of anal function after ISR objectively and accurately, and the high pressure zone and maximum resting pressure (MRP) may be useful 
TABLE 3: Summary of functional results after intersphincteric resection.

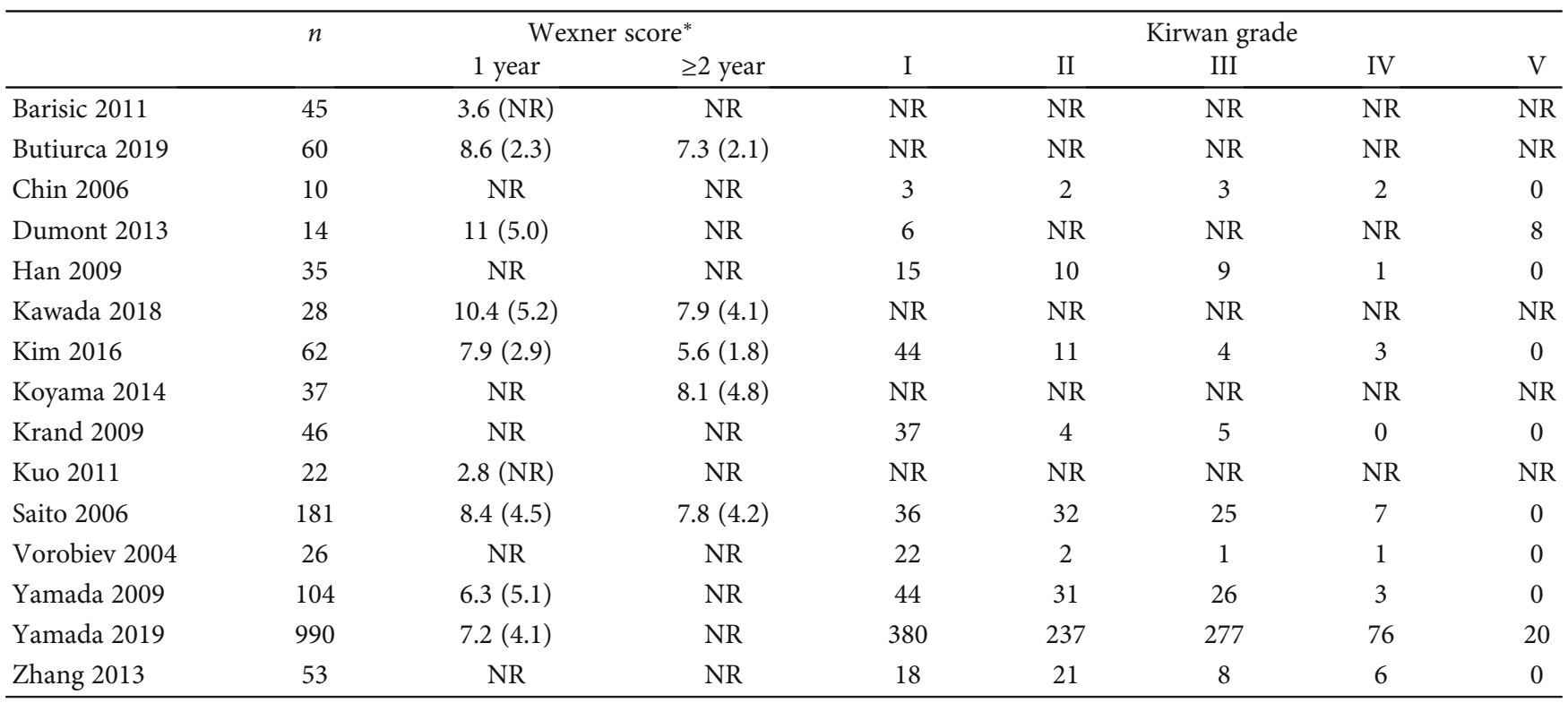

NR: not reported; NS: not sufficient data.

${ }^{*}$ Values are mean (s.d.).

TABLE 4: Summary of functional results after intersphincteric resection.

\begin{tabular}{|c|c|c|c|c|c|c|c|c|c|}
\hline & $n$ & $\begin{array}{c}\text { Mean stool } \\
\text { frequency/24 } \mathrm{h}^{*}\end{array}$ & $\begin{array}{c}\text { Fecal } \\
\text { urgency }\end{array}$ & $\begin{array}{l}\text { Nocturnal } \\
\text { defecation }\end{array}$ & $\begin{array}{c}\text { Pad } \\
\text { wearing }\end{array}$ & $\begin{array}{c}\text { Intestinal transit } \\
\text { regulators }\end{array}$ & $\begin{array}{c}\text { Feces-flatus } \\
\text { discrimination }\end{array}$ & $\begin{array}{c}\text { Stool } \\
\text { fragmentation }\end{array}$ & $\begin{array}{c}\text { Antidiarrhea } \\
\text { medication }\end{array}$ \\
\hline Barisic 2011 & 45 & 1.8 (NR) & NR & NR & NR & NR & NR & NR & NR \\
\hline $\begin{array}{l}\text { Chamlou } \\
2007\end{array}$ & 83 & $2.3(1.3)$ & 16 & 24 & 38 & 22 & 21 & 40 & NR \\
\hline Chin 2006 & 10 & NS & 5 & NR & NR & NR & NR & NR & NR \\
\hline $\begin{array}{l}\text { Dumont } \\
2013\end{array}$ & 14 & NR & 7 & NR & NR & NR & NR & NR & 5 \\
\hline Han 2009 & 35 & $2.7(1.4)$ & 11 & NR & NR & NR & 30 & 15 & 14 \\
\hline Kim 2016 & 62 & $4.0(1.4)$ & NR & NR & NR & NR & NR & NR & NR \\
\hline Koyama 2014 & 37 & $3.7(2.2)$ & NS & NR & NR & NR & NR & NR & 4 \\
\hline Krand 2009 & 46 & NS & 1 & NR & NR & NR & 2 & 7 & 0 \\
\hline Kuo 2011 & 22 & 4.7 (NR) & 4 & 5 & 4 & NR & NR & 8 & 6 \\
\hline $\begin{array}{l}\text { Vorobiev } \\
2004\end{array}$ & 26 & NS & 1 & NR & NR & NR & 3 & 6 & 1 \\
\hline Yamada 2009 & 104 & $3.7(1.6)$ & NR & NR & NR & NR & NR & NR & NR \\
\hline Yamada 2019 & 990 & $5.0(4.0)$ & NR & NR & NR & NR & NR & NR & NR \\
\hline Yoo 2005 & 17 & $5.0(2.0)$ & 10 & 13 & 1 & NR & NR & NR & NR \\
\hline Zhang 2013 & 53 & $3.8(1.3)$ & 12 & 9 & 16 & 13 & 14 & 25 & NR \\
\hline
\end{tabular}

NR: not reported; NS: not sufficient data.

*Values are mean (s.d.).

preoperative predictors of severe FI after ISR. Kitaguchi et al. [85] found that maximum resting pressure and maximum squeeze pressure were significantly lower after ISR, and an elevated incidence of severe FI after ISR was independently related to a high pressure zone before ISR $\leq 3$ $\mathrm{cm}$ and MRP before ISR > $60 \mathrm{mmHg}$. Lately, the fecoflowgrams calculated from defecography has also been a promising assessment of defecation after ISR [86]. Functional results after ISR reported by several studies [7, 11, 60, 80, 87-99] have been summarized in Tables 3 and 4.

Loss of the rectal inhibitory reflex, loss of the rectal storage function, the sphincter lesion caused by instrumental dilatation in stapling or hand-sewed anastomosis, and the disturbed function of the internal sphincter due to the autonomous nerve damage additionally contribute to the anal dysfunction. Regarding the bowel function, the fecal frequency 
after rectal surgery is dependent on the liquid stool present after the excretion of solid stool. Dysfunction of the anal sphincter allows the escape of liquid stool and the loss of the reservoir function cannot retain the liquid stool; therefore, the bowel function is presumably improved by solidifying the liquid stool of postoperative patients [100]. The nerve-sparing mesorectal excision helping to preserve the function of the internal sphincter has been recommended for better continence. Almost 50\% of the patients suffer from an anterior resection syndrome after total or subtotal rectal resection with a straight colorectal or coloanal anastomosis, which describes the characteristic complaints of minor or major incontinence. The anastomosis with the colonic Jpouch has been proved to contribute to better continence in the short-term and long-term compared to the straight anastomosis [101]. Although ARM data show that colonic J-pouch shares identical volume with straight colostomy, the advantage of J-pouch lies in the alleviation of the intestinal motility and subsequent amelioration of the anal function [102]. The convenience of colonic J-pouch anastomosis in defecation frequency, urgency control, storage capacity, fecal incontinence and Wexner score has been reported to be optimized $[103,104]$.

Urinary dysfunction is another notable issue after rectal cancer surgery which may breed detrimental impacts on mental health and QoL of patients. Irritative nocturia and enhanced urinary frequency are the most common among urinary symptoms, $100 \%$ and $75 \%$, respectively. Those symptoms are usually stemmed from mild pelvic neural injury compared to the obstructive symptoms $[105,106]$. The sympathetic nerves from the superior hypogastric plexus and parasympathetic nerves from the pelvic splanchnic nerves control normal bladder and sexual function and are susceptible to injury during TME. Injury to sympathetic nerves may give rise to bladder instability and ejaculatory problems, while injury to the parasympathetic nerves may engender detrusor instability and erectile dysfunction [107]. Many studies have verified that LISR confer better genitourinary outcomes than open approach due to its amplified viewing angle for structure preservation and faster recovery [108, 109].

\section{Conclusion}

The complications, oncological outcomes, and functional outcomes appear to be acceptable after ISR. The ISR technique has been a feasible alternative to APR in selected patients with a low rectal cancer. However, it should be completely discussed with patients before surgery about the postoperative QoL as a result of functional disorder.

\section{Data Availability}

The data used to support the findings of this study are included within the article.

\section{Conflicts of Interest}

All authors declare there is no conflict of interest.

\section{Authors' Contributions}

Yifan Xv, Jiajun Fan, and Qingsong Tao contributed to conception and design; Yifan Xv, Yuan Ding, Yang Hu, Yingjie $\mathrm{Hu}$, and Zhengjie Jiang contributed to literature search, acquisition, analysis, and interpretation; Yifan Xv and Qingsong Tao are responsible for drafting and revising the manuscript; all authors affirmed final approval of the version to be published and agree to be accountable for all aspects of the work in ensuring that questions related to the accuracy or integrity of any part of the work are appropriately investigated and resolved.

\section{Acknowledgments}

This work was supported by Scientific Grant of Nanjing Academic Institute (no. 2015sc513045).

\section{References}

[1] G. Salerno, C. Sinnatamby, G. Branagan, I. R. Daniels, R. J. Heald, and B. J. Moran, "Defining the rectum: surgically, radiologically and anatomically," Colorectal Disease, vol. 8, Supplement 3, pp. 5-9, 2006.

[2] R. Schiessel, J. Karner-Hanusch, F. Herbst, B. Teleky, and M. Wunderlich, "Intersphincteric resection for low rectal tumours," The British Journal of Surgery, vol. 81, no. 9, pp. 1376-1378, 1994.

[3] H. Ueno, H. Mochizuki, Y. Hashiguchi et al., "Preoperative parameters expanding the indication of sphincter preserving surgery in patients with advanced low rectal cancer," Annals of Surgery, vol. 239, no. 1, pp. 34-42, 2004.

[4] E. Rullier, C. Laurent, F. Bretagnol, A. Rullier, V. Vendrely, and F. Zerbib, "Sphincter-saving resection for all rectal carcinomas: the end of the 2-cm distal rule," Annals of Surgery, vol. 241, no. 3, pp. 465-469, 2005.

[5] K. Shirouzu, N. Murakami, and Y. Akagi, "Intersphincteric resection for very low rectal cancer: a review of the updated literature," Annals of Gastroenterological Surgery, vol. 1, no. 1, pp. 24-32, 2017.

[6] S. Mahalingam, R. A. Seshadri, and S. Veeraiah, "Long-term functional and oncological outcomes following intersphincteric resection for low rectal cancers," Indian Journal of Surgical Oncology, vol. 8, no. 4, pp. 457-461, 2017.

[7] M. Koyama, A. Murata, Y. Sakamoto et al., "Long-term clinical and functional results of intersphincteric resection for lower rectal cancer," Annals of Surgical Oncology, vol. 21, Supplement 3, pp. S422-S428, 2014.

[8] Y. H. Ho, S. Brown, S. M. Heah et al., "Comparison of Jpouch and coloplasty pouch for low rectal cancers: a randomized, controlled trial investigating functional results and comparative anastomotic leak rates," Annals of Surgery, vol. 236, no. 1, pp. 49-55, 2002.

[9] Y. Toiyama, J. Hiro, H. Imaoka et al., "Complete laparoscopic total mesorectal excision with an intersphincteric resection and coloplasty pouch anal anastomosis for lower rectal cancer," Journal of the Anus, Rectum and Colon, vol. 1, no. 1, pp. 35-38, 2017.

[10] R. Schiessel, G. Novi, B. Holzer et al., "Technique and longterm results of intersphincteric resection for low rectal 
cancer," Diseases of the Colon and Rectum, vol. 48, no. 10, pp. 1858-1867, 2005, discussion 65-7.

[11] V.-O. Butiurca, C. Molnar, C. Constantin et al., "Long term results of modified intersphincteric resections for low rectal cancer: a single center experience," Medicina, vol. 55, no. 12, p. 764, 2019.

[12] C. Molnar, B. Vlad-Olimpiu, B. Marian, T. Cornelia, and G. Simona, "Survival and functional and oncological outcomes following intersphincteric resection for low rectal cancer: short-term results," The Journal of International Medical Research, vol. 46, no. 4, pp. 1617-1625, 2018.

[13] C. Molnar, C. Nicolescu, B. L. Grigorescu et al., "Comparative oncological outcomes and survival following surgery for low rectal cancer - a single center experience," Revue roumaine de morphologie et Embryologie, vol. 60, no. 3, pp. 847-852, 2019.

[14] W. Xue, S. Wang, Z. Zhao et al., "Short-term outcomes of laparoscopic intersphincteric resection with intraoperative radiotherapy using low-energy X-rays for primary locally advanced low rectal cancer: a single center experience," World Journal of Surgical Oncology, vol. 18, no. 1, p. 26, 2020.

[15] Y. H. Ho, "Techniques for restoring bowel continuity and function after rectal cancer surgery," World Journal of Gastroenterology, vol. 12, no. 39, pp. 6252-6260, 2006.

[16] H. Chen, B. Ma, P. Gao et al., "Laparoscopic intersphincteric resection versus an open approach for low rectal cancer: a meta-analysis," World Journal of Surgical Oncology, vol. 15, no. 1, p. 229, 2017.

[17] D. Mukkai Krishnamurty and P. E. Wise, "Importance of surgical margins in rectal cancer," Journal of Surgical Oncology, vol. 113 , no. 3, pp. 323-332, 2016.

[18] J. G. Guillem, D. B. Chessin, J. Shia et al., “A prospective pathologic analysis using whole-mount sections of rectal cancer following preoperative combined modality therapy: implications for sphincter preservation," Annals of Surgery, vol. 245, no. 1, pp. 88-93, 2007.

[19] K. Bujko, A. Rutkowski, G. J. Chang, W. Michalski, E. Chmielik, and J. Kusnierz, "Is the 1-cm rule of distal bowel resection margin in rectal cancer based on clinical evidence? A systematic review," Annals of Surgical Oncology, vol. 19, no. 3, pp. 801-808, 2012.

[20] H. G. Moore, E. Riedel, B. D. Minsky et al., "Adequacy of 1$\mathrm{cm}$ distal margin after restorative rectal cancer resection with sharp mesorectal excision and preoperative combinedmodality therapy," Annals of Surgical Oncology, vol. 10, no. 1, pp. 80-85, 2003.

[21] M. R. Weiser, H. M. Quah, J. Shia et al., "Sphincter preservation in low rectal cancer is facilitated by preoperative chemoradiation and intersphincteric dissection," Annals of Surgery, vol. 249, no. 2, pp. 236-242, 2009.

[22] K. Kawai, K. Murata, T. Hata et al., "A case of pathological CR in local advanced rectal cancer treated with laparoscopic ISR after XELOXIRI chemotherapy," Gan to kagaku ryoho Cancer \& Chemotherapy, vol. 46, no. 13, pp. 2096-2097, 2019.

[23] S. Okada, H. Kameyama, K. Abe et al., "A case of pathological complete response with neoadjuvant chemotherapy for advanced rectal cancer," Gan to kagaku ryoho Cancer \& chemotherapy, vol. 46, no. 13, pp. 2057-2059, 2019.

[24] M. Wang, W. Xue, Z. Zhao et al., "Laparoscopic intersphincteric resection with intraoperative radiotherapy using low- energy X-rays for locally advanced ultra-low rectal cancer," World Journal of Surgical Oncology, vol. 16, no. 1, p. 133, 2018.

[25] J. Pollack, T. Holm, B. Cedermark, B. Holmström, and A. Mellgren, "Long-term effect of preoperative radiation therapy on anorectal function," Diseases of the Colon and Rectum, vol. 49, no. 3, pp. 345-352, 2006.

[26] K. Ammann, W. Kirchmayr, A. Klaus et al., "Impact of neoadjuvant chemoradiation on anal sphincter function in patients with carcinoma of the midrectum and low rectum," Archives of Surgery, vol. 138, no. 3, pp. 257-261, 2003.

[27] A. E. Canda, C. Terzi, I. B. Gorken, I. Oztop, S. Sokmen, and M. Fuzun, "Effects of preoperative chemoradiotherapy on anal sphincter functions and quality of life in rectal cancer patients," International Journal of Colorectal Disease, vol. 25, no. 2, pp. 197-204, 2010.

[28] G. M. da Silva, M. Berho, S. D. Wexner et al., "Histologic analysis of the irradiated anal sphincter," Diseases of the Colon and Rectum, vol. 46, no. 11, pp. 1492-1497, 2003.

[29] P. Gervaz, N. Rotholtz, S. D. Wexner et al., "Colonic J-pouch function in rectal cancer patients: impact of adjuvant chemoradiotherapy," Diseases of the Colon and Rectum, vol. 44, no. 11, pp. 1667-1675, 2001.

[30] F. B. Beraldo, S. A. I. Yusuf, R. T. Palma, S. Kharmandayan, J. E. Gonçalves, and J. Waisberg, "Urinary dysfunction after surgical treatment for rectal cancer," Arquivos de Gastroenterologia, vol. 52, no. 3, pp. 180-185, 2015.

[31] Q. Y. Qin, T. H. Ma, J. Cai et al., "Clinical features and risk factors of surgical complications after intersphincteric resection for low rectal cancer following neoadjuvant chemoradiotherapy," Zhonghua wai ke za zhi Chinese journal of surgery, vol. 56, no. 12, pp. 892-899, 2018.

[32] J. R. D. Tuson and W. G. Everett, "A retrospective study of colostomies, leaks and strictures after colorectal anastomosis," International Journal of Colorectal Disease, vol. 5, no. 1, pp. 44-48, 1990.

[33] H. Qu, Y. Liu, and D. S. Bi, "Clinical risk factors for anastomotic leakage after laparoscopic anterior resection for rectal cancer: a systematic review and meta-analysis," Surgical Endoscopy, vol. 29, no. 12, pp. 3608-3617, 2015.

[34] K. Kawada and Y. Sakai, "Preoperative, intraoperative and postoperative risk factors for anastomotic leakage after laparoscopic low anterior resection with double stapling technique anastomosis," World Journal of Gastroenterology, vol. 22, no. 25, pp. 5718-5727, 2016.

[35] N. Hyman, T. L. Manchester, T. Osler, B. Burns, and P. A. Cataldo, "Anastomotic leaks after intestinal anastomosis: it's later than you think," Annals of Surgery, vol. 245, no. 2, pp. 254-258, 2007.

[36] U. S. Shin, C. W. Kim, C. S. Yu, and J. C. Kim, "Delayed anastomotic leakage following sphincter-preserving surgery for rectal cancer," International Journal of Colorectal Disease, vol. 25, no. 7, pp. 843-849, 2010.

[37] S. B. Lim, C. S. Yu, C. W. Kim, Y. S. Yoon, I. J. Park, and J. C. Kim, "Late anastomotic leakage after low anterior resection in rectal cancer patients: clinical characteristics and predisposing factors," Colorectal Disease, vol. 18, no. 4, pp. O135O140, 2016

[38] M. Iwamoto, K. Kawada, K. Hida, S. Hasegawa, and Y. Sakai, "Delayed anastomotic leakage following laparoscopic intersphincteric resection for lower rectal cancer: report of four 
cases and literature review," World Journal of Surgical Oncology, vol. 15, no. 1, p. 143, 2017.

[39] M. Yokota, M. Ito, Y. Nishizawa, A. Kobayashi, and N. Saito, "The impact of anastomotic leakage on anal function following Intersphincteric resection," World Journal of Surgery, vol. 41, no. 8, pp. 2168-2177, 2017.

[40] A. Mirnezami, R. Mirnezami, K. Chandrakumaran, K. Sasapu, P. Sagar, and P. Finan, "Increased local recurrence and reduced survival from colorectal cancer following anastomotic leak: systematic review and meta-analysis," Annals of Surgery, vol. 253, no. 5, pp. 890-899, 2011.

[41] D. Aslan, F. Grama, D. Cristian, A. Bordea, and T. Burcoş, "Sphincter-sparing surgery in patients with mid and low rectal cancer-risk factors for local recurrence and anastomotic leakage," Chirurgia (Bucur), vol. 111, no. 6, pp. 481-486, 2016.

[42] K. C. M. J. Peeters, R. A. E. M. Tollenaar, C. A. M. Marijnen et al., "Risk factors for anastomotic failure after total mesorectal excision of rectal cancer," The British Journal of Surgery, vol. 92, no. 2, pp. 211-216, 2005.

[43] J. S. Kim, S. Y. Cho, B. S. Min, and N. K. Kim, "Risk factors for anastomotic leakage after laparoscopic intracorporeal colorectal anastomosis with a double stapling technique," Journal of the American College of Surgeons, vol. 209, no. 6, pp. 694701, 2009.

[44] J. S. Joo, J. F. Latulippe, O. Alabaz, E. G. Weiss, J. J. Nogueras, and S. D. Wexner, "Long-term functional evaluation of straight coloanal anastomosis and colonic J-pouch: is the functional superiority of colonic J-pouch sustained?," Diseases of the Colon and Rectum, vol. 41, no. 6, pp. 740-746, 1998.

[45] D. Kitaguchi, Y. Nishizawa, T. Sasaki, Y. Tsukada, K. Ikeda, and M. Ito, "Recurrence of rectal anastomotic leakage following stoma closure: assessment of risk factors," Colorectal Disease, vol. 21, no. 11, pp. 1304-1311, 2019.

[46] B. C. Paun, S. Cassie, A. R. MacLean, E. Dixon, and W. D. Buie, "Postoperative complications following surgery for rectal cancer," Annals of Surgery, vol. 251, no. 5, pp. 807-818, 2010.

[47] R. L. Whelan, M. Franklin, S. D. Holubar et al., "Postoperative cell mediated immune response is better preserved after laparoscopic vs open colorectal resection in humans," Surgical Endoscopy, vol. 17, no. 6, pp. 972-978, 2003.

[48] P. Matthiessen, O. Hallböök, J. Rutegård, G. Simert, and R. Sjödahl, "Defunctioning stoma reduces symptomatic anastomotic leakage after low anterior resection of the rectum for cancer: a randomized multicenter trial," Annals of Surgery, vol. 246, no. 2, pp. 207-214, 2007.

[49] M. T. Eriksen, A. Wibe, J. Norstein, J. Haffner, J. N. Wiig, and the Norwegian Rectal Cancer Group, "Anastomotic leakage following routine mesorectal excision for rectal cancer in a national cohort of patients," Colorectal Disease, vol. 7, no. 1, pp. 51-57, 2005.

[50] B. Lefebure, J. J. Tuech, V. Bridoux et al., "Evaluation of selective defunctioning stoma after low anterior resection for rectal cancer," International Journal of Colorectal Disease, vol. 23, no. 3, pp. 283-288, 2008.

[51] A. Kraenzler, L. Maggiori, O. Pittet, M. S. Alyami, J. Prost à la Denise, and Y. Panis, "Anastomotic stenosis after coloanal, colorectal and ileoanal anastomosis: what is the best management?," Colorectal Disease, vol. 19, no. 2, pp. O90-O96, 2017.
[52] S. Y. Lee, C. H. Kim, Y. J. Kim, and H. R. Kim, “Anastomotic stricture after ultralow anterior resection or intersphincteric resection for very low-lying rectal cancer," Surgical Endoscopy, vol. 32, no. 2, pp. 660-666, 2018.

[53] B. Zhang, G. Z. Zhuo, L. Tian et al., "Risk factors of coloanal anastomotic stricture after laparoscopic intersphincteric resection for low rectal cancer," Zhonghua wei chang Wai Ke Za Zhi, vol. 22, no. 8, pp. 755-761, 2019.

[54] M. J. Johnston, G. M. Robertson, and F. A. Frizelle, "Management of late complications of pelvic radiation in the rectum and anus: a review," Diseases of the Colon and Rectum, vol. 46, no. 2, pp. 247-259, 2003.

[55] V. S. Theis, R. Sripadam, V. Ramani, and S. Lal, "Chronic radiation enteritis," Clinical Oncology, vol. 22, no. 1, pp. 7083, 2010.

[56] G. Brisinda, S. Vanella, F. Cadeddu et al., "Surgical treatment of anal stenosis," World Journal of Gastroenterology, vol. 15, no. 16, pp. 1921-1928, 2009.

[57] Y. Zhao, X. Hou, Y. Zhao, Y. Feng, B. Zhang, and K. Zhao, "Risk factors of postoperative urinary retention after rectal cancer surgery," Zhonghua Wei Chang Wai Ke Za Zhi, vol. 20, no. 3, pp. 295-299, 2017.

[58] I. J. Park and J. C. Kim, "Intersphincteric resection for patients with low-lying rectal cancer: oncological and functional outcomes," Annals of Coloproctology, vol. 34, no. 4, pp. 167-174, 2018.

[59] T. Akasu, M. Takawa, S. Yamamoto et al., "Intersphincteric resection for very low rectal adenocarcinoma: univariate and multivariate analyses of risk factors for recurrence," Annals of Surgical Oncology, vol. 15, no. 10, pp. 2668-2676, 2008.

[60] R. Chamlou, Y. Parc, T. Simon et al., "Long-term results of intersphincteric resection for low rectal cancer," Annals of Surgery, vol. 246, no. 6, pp. 916-922, 2007, discussion 21-2.

[61] T. Akasu, M. Takawa, S. Yamamoto, S. Fujita, and Y. Moriya, "Incidence and patterns of recurrence after intersphincteric resection for very low rectal adenocarcinoma," Journal of the American College of Surgeons, vol. 205, no. 5, pp. 642647, 2007.

[62] N. Saito, M. Ito, A. Kobayashi et al., "Long-term outcomes after intersphincteric resection for low-lying rectal cancer," Annals of Surgical Oncology, vol. 21, no. 11, pp. 3608-3615, 2014.

[63] W. Hohenberger, S. Merkel, K. Matzel, B. Bittorf, T. Papadopoulos, and J. Gohl, "The influence of abdominoperanal (intersphincteric) resection of lower third rectal carcinoma on the rates of sphincter preservation and locoregional recurrence," Colorectal Disease, vol. 8, no. 1, pp. 23-33, 2006.

[64] Y. Akagi, K. Shirouzu, Y. Ogata, and T. Kinugasa, "Oncologic outcomes of intersphincteric resection without preoperative chemoradiotherapy for very low rectal cancer," Surgical Oncology, vol. 22, no. 2, pp. 144-149, 2013.

[65] A. Sakr, S. Y. Yang, J. H. Kang et al., "Oncologic safety and bowel function after ultralow anterior resection with or without intersphincteric resection for low lying rectal cancer: comparative cross sectional study," Journal of Surgical Oncology, vol. 121, no. 2, pp. 365-374, 2019.

[66] J. S. Park, N. K. Kim, S. H. Kim et al., "Multicentre study of robotic intersphincteric resection for low rectal cancer," The 
British Journal of Surgery, vol. 102, no. 12, pp. 1567-1573, 2015.

[67] G. Portier, L. Ghouti, S. Kirzin, R. Guimbaud, M. Rives, and F. Lazorthes, "Oncological outcome of ultra-low coloanal anastomosis with and without intersphincteric resection for low rectal adenocarcinoma," The British Journal of Surgery, vol. 94, no. 3, pp. 341-345, 2007.

[68] X. Zhang, Q. Wu, T. Hu, C. Gu, L. Bi, and Z. Wang, "Laparoscopic versus conventional open surgery in intersphincteric resection for low rectal cancer: a systematic review and meta-analysis," Journal of laparoendoscopic \& Advanced Surgical Techniques Part A, vol. 28, no. 2, pp. 189-200, 2018.

[69] S. H. Lee, D. H. Kim, and S. W. Lim, "Robotic versus laparoscopic intersphincteric resection for low rectal cancer: a systematic review and meta-analysis," International Journal of Colorectal Disease, vol. 33, no. 12, pp. 1741-1753, 2018.

[70] L. J. Kuo, Y. K. Lin, C. C. Chang, C. J. Tai, J. F. Chiou, and Y. J. Chang, "Clinical outcomes of robot-assisted intersphincteric resection for low rectal cancer: comparison with conventional laparoscopy and multifactorial analysis of the learning curve for robotic surgery," International Journal of Colorectal Disease, vol. 29, no. 5, pp. 555-562, 2014.

[71] S. Y. Park, G. S. Choi, J. S. Park, H. J. Kim, and J. P. Ryuk, "Short-term clinical outcome of robot-assisted intersphincteric resection for low rectal cancer: a retrospective comparison with conventional laparoscopy," Surgical Endoscopy, vol. 27, no. 1, pp. 48-55, 2013.

[72] B. E. Yoo, J. S. Cho, J. W. Shin et al., "Robotic versus laparoscopic intersphincteric resection for low rectal cancer: comparison of the operative, oncological, and functional outcomes," Annals of Surgical Oncology, vol. 22, no. 4, pp. 1219-1225, 2015.

[73] P. Chi, S. H. Huang, H. M. Lin et al., "Laparoscopic transabdominal approach partial intersphincteric resection for low rectal cancer: surgical feasibility and intermediate-term outcome," Annals of Surgical Oncology, vol. 22, no. 3, pp. 944951, 2015.

[74] Y. Fujimoto, T. Akiyoshi, H. Kuroyanagi et al., "Safety and feasibility of laparoscopic intersphincteric resection for very low rectal cancer," Journal of Gastrointestinal Surgery, vol. 14, no. 4, pp. 645-650, 2010.

[75] L. J. Kuo, C. S. Hung, W. Wang et al., "Intersphincteric resection for very low rectal cancer: clinical outcomes of open versus laparoscopic approach and multidimensional analysis of the learning curve for laparoscopic surgery," The Journal of Surgical Research, vol. 183, no. 2, pp. 524-530, 2013.

[76] C. Laurent, T. Paumet, F. Leblanc, Q. Denost, and E. Rullier, "Intersphincteric resection for low rectal cancer: laparoscopic vs open surgery approach," Colorectal Disease, vol. 14, no. 1, pp. 35-41, 2012, discussion 2-3.

[77] J. S. Park, G. S. Choi, S. H. Jun, S. Hasegawa, and Y. Sakai, "Laparoscopic versus open intersphincteric resection and coloanal anastomosis for low rectal cancer: intermediateterm oncologic outcomes," Annals of Surgery, vol. 254, no. 6, pp. 941-946, 2011.

[78] S. Yamamoto, S. Fujita, T. Akasu, R. Inada, M. Takawa, and Y. Moriya, "Short-term outcomes of laparoscopic intersphincteric resection for lower rectal cancer and comparison with open approach," Digestive Surgery, vol. 28, no. 5-6, pp. 404-409, 2011.

[79] M. Ito, N. Saito, M. Sugito, A. Kobayashi, Y. Nishizawa, and Y. Tsunoda, "Analysis of clinical factors associated with anal function after intersphincteric resection for very low rectal cancer," Diseases of the Colon and Rectum, vol. 52, no. 1, pp. 64-70, 2009.

[80] K. Yamada, S. Ogata, Y. Saiki, M. Fukunaga, Y. Tsuji, and M. Takano, "Long-term results of intersphincteric resection for low rectal cancer," Diseases of the Colon and Rectum, vol. 52, no. 6, pp. 1065-1071, 2009.

[81] H. Shiokawa, K. Funahashi, H. Kaneko, and T. Teramoto, "Long-term assessment of anorectal function after extensive resection of the internal anal sphincter for treatment of low-lying rectal cancer near the anus," Journal of the Anus, Rectum and Colon, vol. 1, no. 1, pp. 29-34, 2017.

[82] S. Huang, P. Chi, H. Lin et al., "Short-term efficacy comparison of laparoscopic versus open transabdominal intersphincteric resection for low rectal cancer," Zhonghua Wei Chang Wwai Ke Za Zhi, vol. 19, no. 8, pp. 923-927, 2016.

[83] A. E. Bharucha, J. G. Fletcher, C. M. Harper et al., "Relationship between symptoms and disordered continence mechanisms in women with idiopathic faecal incontinence," Gut, vol. 54, no. 4, pp. 546-555, 2005.

[84] A. E. Bharucha and S. S. C. Rao, "An update on anorectal disorders for gastroenterologists," Gastroenterology, vol. 146, no. 1, pp. 37-45.e2, 2014.

[85] D. Kitaguchi, Y. Nishizawa, T. Sasaki, Y. Tsukada, and M. Ito, "Clinical benefit of high resolution anorectal manometry for the evaluation of anal function after intersphincteric resection," Colorectal Disease, vol. 21, no. 3, pp. 335-341, 2019.

[86] H. Kawahara, T. Mouri, K. Ishida, N. Matsumoto, T. Akiba, and K. Yanaga, "Usefulness of fecoflowgram for assessment of defecation after intersphincteric resection," Digestion, vol. 98, no. 2, pp. 81-86, 2018.

[87] G. Barisic, V. Markovic, M. Popovic, I. Dimitrijevic, P. Gavrilovic, and Z. Krivokapic, "Function after intersphincteric resection for low rectal cancer and its influence on quality of life," Colorectal Disease, vol. 13, no. 6, pp. 638-643, 2011.

[88] C. C. Chin, C. Y. Yeh, W. S. Huang, and J. Y. Wang, "Clinical outcome of intersphincteric resection for ultra-low rectal cancer," World Journal of Gastroenterology, vol. 12, no. 4, pp. 640-643, 2006.

[89] F. Dumont, M. Ayadi, D. Goéré, C. Honoré, and D. Elias, "Comparison of fecal continence and quality of life between intersphincteric resection and abdominoperineal resection plus perineal colostomy for ultra-low rectal cancer," Journal of Surgical Oncology, vol. 108, no. 4, pp. 225-229, 2013.

[90] J. G. Han, G. H. Wei, Z. G. Gao, Y. Zheng, and Z. J. Wang, "Intersphincteric resection with direct coloanal anastomosis for ultralow rectal cancer: the experience of People's Republic of China," Diseases of the Colon and Rectum, vol. 52, no. 5, pp. 950-957, 2009.

[91] K. Kawada, K. Hida, S. Hasegawa, and Y. Sakai, “A comparison of the long-term anorectal function between laparoscopic intersphincteric resection and low anterior resection for low rectal cancer," Surgery Today, vol. 48, no. 10, pp. 921-927, 2018.

[92] H. S. Kim, S. Ko, and N.-g. Oh, "Long-term results of extended intersphincteric resection for very low rectal cancer: a retrospective study," BMC Surgery, vol. 16, no. 1, p. 21, 2016.

[93] O. Krand, T. Yalti, G. Tellioglu, M. Kara, I. Berber, and M. I. Titiz, "Use of smooth muscle plasty after intersphincteric 
rectal resection to replace a partially resected internal anal sphincter: long-term follow-up," Diseases of the Colon and Rectum, vol. 52, no. 11, pp. 1895-1901, 2009.

[94] L. J. Kuo, C. S. Hung, C. H. Wu et al., "Oncological and functional outcomes of intersphincteric resection for low rectal cancer," The Journal of Surgical Research, vol. 170, no. 1, pp. e93-e98, 2011.

[95] N. Saito, Y. Moriya, K. Shirouzu et al., "Intersphincteric resection in patients with very low rectal cancer: a review of the Japanese experience," Diseases of the Colon and Rectum, vol. 49, 10 Suppl, pp. S13-S22, 2006.

[96] G. I. Vorobiev, T. S. Odaryuk, P. V. Tsarkov, A. I. Talalakin, and E. G. Rybakov, "Resection of the rectum and total excision of the internal anal sphincter with smooth muscle plasty and colonic pouch for treatment of ultralow rectal carcinoma," The British Journal of Surgery, vol. 91, no. 11, pp. 1506-1512, 2004.

[97] K. Yamada, Y. Saiki, S. Takano et al., "Long-term results of intersphincteric resection for low rectal cancer in Japan," Surgery Today, vol. 49, no. 4, pp. 275-285, 2019.

[98] J. H. Yoo, H. Hasegawa, Y. Ishii, H. Nishibori, M. Watanabe, and M. Kitajima, "Long-term outcome of per anum intersphincteric rectal dissection with direct coloanal anastomosis for lower rectal cancer," Colorectal Disease, vol. 7, no. 5, pp. 434-440, 2005.

[99] Y. J. Zhang, L. Yin, L. Huang, H. B. Zhang, Y. Han, and M. B. Lin, "Long-term results of intersphincteric resection for low rectal cancer," Journal of Investigative Surgery, vol. 26, no. 4, pp. 217-222, 2013.

[100] N. Beppu, K. Fumihiko, D. Hiroshi et al., "Functional outcomes of patients treated with intensive medications for bowel and pain control for low-lying rectal cancer who received preoperative chemoradiotherapy," Digestive Surgery, vol. 33, no. 5, pp. 431-438, 2016.

[101] E. Gross and G. Möslein, "Colonic pouch and other procedures to improve the continence after low anterior rectal resection with TME," Zentralblatt fur Chirurgie, vol. 133, no. 2, pp. 107-115, 2008.

[102] A. Fürst, S. Suttner, A. Agha, A. Beham, and K. W. Jauch, "Colonic J-pouch vs. coloplasty following resection of distal rectal cancer: early results of a prospective, randomized, pilot study," Diseases of the Colon and Rectum, vol. 46, no. 9, pp. 1161-1166, 2003.

[103] H. S. Tilney and P. P. Tekkis, "Extending the horizons of restorative rectal surgery: intersphincteric resection for low rectal cancer," Colorectal Disease, vol. 10, no. 1, pp. 3-15, 2008.

[104] F. Bretagnol, E. Rullier, C. Laurent, F. Zerbib, R. Gontier, and J. Saric, "Comparison of functional results and quality of life between intersphincteric resection and conventional coloanal anastomosis for low rectal cancer," Diseases of the Colon and Rectum, vol. 47, no. 6, pp. 832-838, 2004.

[105] D. Moszkowicz, B. Alsaid, T. Bessede et al., "Where does pelvic nerve injury occur during rectal surgery for cancer?," Colorectal Disease, vol. 13, no. 12, pp. 1326-1334, 2011.

[106] C. Eveno, A. Lamblin, C. Mariette, and M. Pocard, "Sexual and urinary dysfunction after proctectomy for rectal cancer," Journal of Visceral Surgery, vol. 147, no. 1, pp. e21-e30, 2010.

[107] R. S. Lim, T. X. Yang, and T. C. Chua, "Postoperative bladder and sexual function in patients undergoing surgery for rectal cancer: a systematic review and meta-analysis of laparoscopic versus open resection of rectal cancer," Techniques in Coloproctology, vol. 18, no. 11, pp. 993-1002, 2014.

[108] O. Asoglu, T. Matlim, H. Karanlik et al., "Impact of laparoscopic surgery on bladder and sexual function after total mesorectal excision for rectal cancer," Surgical Endoscopy, vol. 23, no. 2, pp. 296-303, 2009.

[109] E. R. McGlone, O. Khan, K. Flashman, J. Khan, and A. Parvaiz, "Urogenital function following laparoscopic and open rectal cancer resection: a comparative study," Surgical Endoscopy, vol. 26, no. 9, pp. 2559-2565, 2012. 